\title{
Seismic performance of ductile connections between precast beams and roof elements
}

\author{
Andrea Belleri, Mauro Torquati, Paolo Riva
}

\begin{abstract}
Authors:
Andrea Belleri, Ph.D.

Post doctoral researcher at the department of Engineering, University of Bergamo, Italy

Mauro Torquati

Graduate student at the department of Engineering, University of Bergamo, Italy

Paolo Riva, Ph.D. Full Professor

Department of Engineering, University of Bergamo, Italy
\end{abstract}

Corresponding author:

Andrea Belleri

Department of Engineering, University of Bergamo

Viale Marconi 5, 24044, Dalmine - Italy

Telephone number: +390352052007

email: andrea.belleri@unibg.it

Total number of words in the main text and tables

$=>$

4994

Total number of figures

$=>$

6 


\section{Abstract}

The seismic vulnerability of precast reinforced concrete buildings is often governed by the performance of mechanical connections between precast elements. This aspect was highlighted by recent seismic events in Italy where several collapses were registered among industrial buildings typical of Italian practice. The building damage was related to failure of connections between beams and columns and between beams and roof elements which led to the loss of support of the structural elements.

Starting from the results of an experimental campaign, the present work investigates the use of ductile connections between precast beams and roof elements suitable for both new structures and as a retrofit measure of existing ones. These connections are able to transfer the horizontal inertial loads and to accommodate deformations arising from seismic displacement compatibility. The relative rotation between the end of the roof elements and the beam, due to seismic displacement demand, could lead to their contact. This leads to a load increase in rigid connections, which can cause their premature failure, or to horizontal relative displacements as in the ductile connections considered herein. Moreover the connections investigated could be used to dissipate seismic energy.

\section{List of notation}

$$
\begin{array}{ll}
U_{i} & \text { dissipated energy at the } i^{\text {th }} \text { cycle } \\
U_{0 i} & \text { elastic energy at the } i^{\text {th }} \text { cycle } \\
d & \text { device displacement } \\
d_{\text {yield }} & \text { yield displacement } \\
d_{\text {max }, i} & \text { maximum displacement at the } i^{\text {th }} \text { cycle } \\
d_{\text {ult }} & \text { ultimate displacement } \\
F & \text { device force component } \\
F_{\text {yield }} & \text { yield force } \\
F_{\text {max }, i} & \text { maximum applied force at the } i^{\text {th }} \text { cycle } \\
F_{\text {ult }} & \text { ultimate force } \\
\mu_{\Delta} & \text { displacement ductility } \\
N C R & \text { no-collapse requirement } \\
E & \text { elastic modulus } \\
f_{y k} & \text { characteristic yield stress } \\
f_{\text {tk }} & \text { characteristic ultimate stress } \\
\phi & \text { rod diameter } \\
r & \text { rod bending radius } \\
\mathrm{I} & \text { rod section moment of inertia }\left(\pi \phi^{4} / 64\right) \\
Z & \text { rod section plastic modulus }\left(\phi^{3} / 6\right) \\
\xi & \text { relative damping } \\
\varepsilon_{u l t} & \text { ultimate tensile strain } \\
& \\
\hline
\end{array}
$$




\section{ICE keywords}

Seismic Engineering; Buildings, structures \& design; Concrete structures; 


\section{Introduction}

In May 2012 significant damage was recorded in precast concrete structures after two major earthquakes in Northern Italy, in a region characterized by a high concentration of industrial facilities and warehouses built according to traditional Italian precast concrete building practice. The typical structural layout of these buildings consists of one storey frames with fixed ended cantilever columns placed in isolated cup footings or connected to the foundation by means of mechanical connectors or grouted sleeve solutions (Osanai et al., 1996; Blandon and Rodriguez, 2005; Metelli and Riva, 2008; Belleri and Riva, 2012). The top of the columns is dowel connected to prestressed beams supporting prestressed roof elements. Although the current building code, according to BS EN 1998-1:2004 (BSI, 2005), enforces mechanical connections between structural elements, most of the damaged buildings were constructed before the definition of seismic design regulations and the horizontal force transfer between precast beams and columns and between roof elements and beams was often provided by friction or by steel dowel connections not specifically designed for seismic loads. The inadequacy of these connections led to the loss of support of the structural elements in the aforementioned earthquakes, being the seismic displacement demand for these structures higher than traditional reinforced concrete frames due to the static scheme, fix end cantilever, and to the large inter-storey height.

Another possible consequence of the high flexibility is a change of the joints stiffness: the contact between adjacent elements, as the roof panel and the supporting beam (Figure 1), due to their relative rotation during a seismic event, modifies the static scheme and the joint gains a degree of fixity which leads to the development of additional forces not considered during design. Therefore the connections should be designed to be in equilibrium with the seismic forces and to accommodate displacement and rotation compatibility between adjacent elements, being the displacement and rotation demand concentrated at the connections due to their lower stiffness compared to the connected precast concrete elements.

The structure high flexibility leads to a seismic design governed by displacement rather than material strain control, due to the necessity to limit damage to non-structural members, such as the peripheral cladding panels, and to control second order effects. Moreover, the resultant displacement ductility is low and therefore the hysteretic energy dissipated during earthquakes is also low, the dissipation mechanism being the development of a plastic hinge at the column base. Improved seismic performances could be achieved with cast in place joints to emulate the behaviour of traditional monolithic reinforced concrete structures (Restrepo et al., 1995). However, the additional work required in the construction field increases the building cost compared to traditional mechanical connections. An alternative solution could be represented by placing additional energy dissipation devices compatible with the traditional construction technique or design dissipative dry connections.

The present paper focuses on mechanical connections between roof elements and supporting beams. Starting from the analysis of the current connection types and building code 
requirements, the paper investigates the seismic performance and design of a new ductile connection suitable for both new structures and as a retrofit measure for existing ones. The proposed connection is able to accommodate relative rotations between adjacent elements, as in Figure 1, and to dissipate energy if detailed appropriately. Capacity design could be easily applied to ensure full plastic development of the connection. The results and the considerations outlined in the paper could be extended to other ductile connections different from the one investigated.

\section{Precast beam - roof connections}

According to BS EN 1998-1:2004 (BSI, 2005), precast connections are classified based on their position compared to the energy dissipation regions of the structure. Three types of connections are identified: (i) connections placed outside critical regions and not affecting the energy dissipation capacity of the structure; (ii) connections placed inside critical regions but overdesigned in order to remain elastic in the seismic design situation; (iii) connections placed inside critical regions and detailed in order to develop substantial ductility and dissipation capacity in the seismic design situation.

For precast frames with hinged connections between columns and beams, as in the one storey precast concrete buildings considered, the energy dissipation during a seismic event is provided by the development of a plastic hinge at the column base, therefore the connections between roof elements and supporting beams are usually identified as type (i) and designed to carry a seismic shear force obtained applying capacity design: the shear force associated with the development of the plastic hinge at the column base accounting for steel overstrength with an appropriate factor depending on the ductility class ( 1.1 for medium ductility class and 1.3 for high ductility class). These connections are considered as hinged in the structural static scheme and therefore bending moment resistance is not taken into account in the design process.

Regarding floor/roof elements, BS EN 1998-1:2004 (BSI, 2005) provides indications of the structural details that enable a diaphragm action. During a seismic event the floor diaphragm, if detailed appropriately, provides the horizontal floor loads transfer to the vertical lateral load resisting system. In addition, the floor diaphragm is in charge of collecting the horizontal seismic loads of the gravity load system, such as beams and columns. Although for low seismicity sites it is possible to obtain a precast floor diaphragm with solely mechanical connections (Schoettler et al., 2009), the diaphragm action of precast floors and roofs is usually provided by an appropriate topping of in-situ reinforced concrete. A cast-in-place topping with a thickness of 70 $\mathrm{mm}$, reinforced in both horizontal directions with at least minimum reinforcement, may be considered as a diaphragm provided it has enough stiffness and resistance and it is cast over a clean, rough substrate or connected to it by shear keys to avoid delamination and allow horizontal load transfer from the substrate to the diaphragm itself. The in-plane shear forces in the slab-slab or slab-beam connections are to be designed with an overdesign factor of 1.30 .

In the type of precast buildings under investigation, the roof could rarely be considered as a diaphragm: roof elements, such double tee units, are not connected to each other, there are 
connections only at the supporting beams, in situ topping are rarely provided and there are often large openings for illumination purposes. This leads to highly flexible roofs with no diaphragm action and therefore to the necessity of a distributed vertical lateral load resisting system as with fixed ended cantilever columns.

The typical precast beam - roof connection adopted in the considered buildings is made by commercial L-shape steel plates. These are bolt connected to the roof element stems with through thickness dowels and to the beam by means of anchor head bolts placed in steel channel profiles embedded in the supporting beam. The use of anchor channels and slotted connections is necessary for tolerance issues. The L-shape steel plate is the stiff element of the connection and is characterized by high strength compared to the other components. This leads to a connection failure associated with concrete crushing and spalling (Palermo et al., 2008) or anchor channel lips tearing off due to prying action of the anchor headed bolts. A ductile failure could be obtained by replacing the commercial L-shape steel plates with thinner bent plates (Felicetti et al., 2008). A ductile connection allows the application of the capacity design rule to all the components and accommodates relative movements of the connected precast elements. As mentioned before, the relative rotations between roof elements and the supporting beams, associated with horizontal seismic forces, are not generally considered in the design process. The connections between these elements are modelled as hinges and displacement compatibility between the connected elements is not specifically accounted for, although in recent earthquakes (Lauciani et al., 2012) this was one of the reasons of the collapse of industrial precast concrete buildings. In fact, the contact between the roof element and the supporting beam due to their relative rotation increases the rotational stiffness of the considered sub-assemblage compared to the ideal hinged solution. The moment-rotation relationship is different for clockwise and counter-clockwise relative rotations. Taking as reference Figure 1, if the supporting beam is subjected to counter-clockwise rotations, the connection can be considered as a hinge and contact does not occur. In the case of clockwise rotations, the supporting beam can rotate until closure of the gap between the two structural elements, then the sub-assemblage gains rotational stiffness.

The high rigidity of most of the connection systems adopted in current practice, together with their inability to exhibit ductile behaviour, leads to a fragile failure of the connections if higher horizontal forces arise due to higher seismic demand or to relative rotation between adjacent elements. After failure of the connections, the precast roof elements have no horizontal restraints to avoid loss of support and falling during the earthquake. This problem could be bypassed by the arch shape ductile connection presented herein. 


\section{Arch shape ductile connection}

\subsection{Connection description and configuration}

The precast beam - roof ductile connection investigated consists of two curved circular steel rods welded to rectangular plates anchored to the structural elements (Figure 2). This Arch Shape Ductile Connection (ASDC) could be adopted for both existing and new precast buildings. If the connection is used as a retrofit measure, with or without the presence of traditional connections, the rectangular plates are fixed to the structural elements with chemical or mechanical fasteners. For new structures, the plates are directly connected to the structural elements by means of anchor channels, which allow tolerance adjustments.

As shown in Figure 2, different configurations are possible for the considered ASDC. It can work in the rod plane (in-plane deformations, Figure 2e) or in the perpendicular direction (out-of-plane deformations, Figure 2d). The connection stiffness and strength is different in the two directions as will be shown in the next paragraph. In both configurations this device is able to accommodate relative displacements between the adjacent connected elements controlling the transferred horizontal force. The moment generated by the contact of roof elements and supporting beams is computed as the product of the device force and the distance between the device and the precast elements contact point (Figure 1). Other configurations are possible when the device is adopted as a retrofit measure for existing hinged connections between roof elements and supporting beams (Figure 2f). In this case, only relative rotations between adjacent precast elements are allowed and the ASDC could act as an energy dissipation device activated by relative rotations between the connected elements, provided there is enough space to avoid contact at the elements top.

\subsection{Experimental tests and analytical models}

Experimental tests were performed to investigate the mechanical behaviour of the proposed ductile connection. Quasi static cyclic tests were carried out in the in-plane and out-of-plane ASDC directions in displacement control by means of a tension-compression hydraulic testing machine in the Structural Lab of the University of Bergamo, Italy. Only single devices are tested because the ASDC strength and stiffness are significantly lower compared to the connected precast concrete elements. The tested devices are made by two arch rods, S235 grade, with 12 $\mathrm{mm}$ diameter $(\phi)$ and a bending radius ( $\mathrm{r}$ ) of $75 \mathrm{~mm}$ fillet welded to the plates (Figure $2 \mathrm{~b}$ ).

Figure 3 shows the results of the cyclic tests in terms of load-displacement and dimensionless energy-displacement ductility. The dimensionless energy is defined as the ratio of the dissipated energy in each cycle $\left(U_{i}\right)$, area inside a force-displacement cycle, and the corresponding elastic energy $\left(U_{0 i}\right)$ :

$$
U_{0 i}=\frac{d_{\max , i}^{+} \cdot F_{\max , i}^{+}}{2}+\frac{d_{\max , i}^{-} \cdot F_{\max , i}^{-}}{2}
$$


Where $\mathrm{d}_{\text {max,i, }}^{+}, \mathrm{F}_{\text {max,i }}^{+}$and $\mathrm{d}_{\text {max,i, }}^{-}, \mathrm{F}_{\text {max,i }}^{-}$are the maximum force and displacement of each cycle, in absolute terms, in the positive and negative direction, respectively. The displacement ductility is the ratio between actual and yield displacement $\left(\mu_{\Delta}=d / d_{y}\right)$.

The experimental results highlight a good behaviour of the connection system in terms of ductility, strength and dissipative capacity. In the load - displacement diagrams geometric nonlinearity is evident, leading to a stiffening effect during rods straightening. The out-of-plane deformations have a symmetric hysteretic behaviour and higher displacement capacity compared to in-plane deformations, where negative displacements are characterized by a softening behaviour. The dimensionless energy dissipation capacity is similar in both cases although slightly higher values are recorded for in-plane deformations. The failure of the connection is associated with fracture of the steel rods due to excessive bending deformations at the rod edges, close to the fillet welding (Figure $2 b$ ), in the thermally affected region. A possible improvement of the device performance is obtained with the welding solution shown in Figure 2c: the rods are placed inside holes in the plates and fillet welded from behind to avoid bending deformation in the thermally affected region.

To extend the experimental results to different ASDC geometries, an analytical formulation is developed for both in-plane and out-of-plane directions. For this purpose the yield and ultimate points in the force - displacement graph are defined analytically following the static scheme in Figure 4.

For in-plane deformations, displacements in the y direction, the initial elastic stiffness (Yamada and Ezawa, 1977) in the case of an arch rod extending one quarter of a circle the stiffness is:

$$
k_{y}=\frac{E l}{r^{3}} \frac{0.6169-\frac{0.5}{1+0.0625(\phi / r)^{2}}}{0.2881\left(1+0.0625(\phi / r)^{2}\right)-0.2854}
$$

The yield force, $F_{y, y i e l d}$, is evaluated considering the development of 3 plastic hinges, $M_{\mathrm{pl}}=\mathrm{Z} \times \mathrm{f}_{\mathrm{yk}}$, and applying the equilibrium of half rod in the un-deformed configuration (Figure 4a):

$$
F_{y, \text { yield }}=\frac{4}{\sqrt{2}} \frac{M_{p l}}{r(2-\sqrt{2})}
$$

The yield displacement is obtained as the ratio of yield force and stiffness $\left(d_{y, y i e l d}=F_{y, y i e l d} / k_{y}\right)$. The ultimate displacement and force are evaluated considering the straightening of the arch rod in the y direction (Figure $4 \mathrm{~b}$ ) and the rod elongation associated with axial failure:

$$
\begin{aligned}
& d_{y, u l t}=\sqrt{\left(\frac{r \pi}{2}\left(1+\varepsilon_{u l t}\right)\right)^{2}-r^{2}}-r \\
& F_{y, \text { ult }}=2 f_{t k} A \frac{r+d_{y, u l t}}{\pi r\left(1+\varepsilon_{u l t}\right)}
\end{aligned}
$$


In the opposite direction, characterized by a softening behaviour due to geometric nonlinearities, the point necessary to describe the load-displacement descending branch is (-r/2; $F_{y, \text { yield }} / 2$ ).

For out-of-plane deformations, displacements in the $z$ direction, the initial elastic stiffness is obtained directly as:

$$
k_{z}=12 \frac{E l}{(r \pi / 2)^{3}}
$$

The yield force, $F_{z, \text { yield }}$, is evaluated considering the development of a plastic hinge at each rod edge (Figure 4c):

$$
F_{z, \text { yield }}=\sqrt{2} \frac{M_{p l}}{r}
$$

The yield displacement is obtained as the ratio of yield force and stiffness $\left(d_{z \text {,yield }}=F_{z, \text { yield }} / k_{z}\right)$. The ultimate displacement and force are evaluated considering the straightening of the arch rod in the $\mathrm{z}$ direction (Figure $4 \mathrm{~d}$ ) and the rod elongation associated to axial failure:

$$
\begin{aligned}
& d_{z, \text { ult }}=\sqrt{\left(\frac{r \pi}{2}\left(1+\varepsilon_{\text {ult }}\right)\right)^{2}-2 r^{2}} \\
& F_{z, \text { ult }}=2 f_{t k} A \frac{d_{z, \text { ult }}}{\pi r\left(1+\varepsilon_{\text {ult }}\right)}
\end{aligned}
$$

To investigate the suitability of the proposed analytical formulation, selected geometries are modelled in the finite element software ABAQUS 6.11 (Dassault Systèmes Simulia Corp., 2011) to determine the load-displacement relationship in the $y$ and $z$ direction. The rod diameters, $\phi$, chosen in the simulations are 12,16, $20 \mathrm{~mm}$, while the bending radii, $r$, are 75, 100, 150 and $200 \mathrm{~mm}$. Only a single rod is modelled: being the two rods in parallel, the device behaviour is obtained by multiplying by two the forces found in a single rod analysis while keeping the same displacements. Characteristic S235 steel values are considered in the definition of the material stress-strain model adopted in the analyses: an elasto-plastic bilinear behaviour is chosen with yield and ultimate points $\left(\mathrm{f}_{\mathrm{yk}} / \mathrm{E} ; \mathrm{f}_{\mathrm{yk}}\right)$ and $\left(0.2 ; \mathrm{f}_{\mathrm{tk}}\right)$ respectively, where $\mathrm{f}_{\mathrm{yk}}=235 \mathrm{MPa}, \mathrm{f}_{\mathrm{tk}}=360 \mathrm{MPa}$ and $\mathrm{E}=205000 \mathrm{MPa}$.

The finite element comparison with the experimental data and the analytical formulation is shown in Figure 3 and Figure 5, respectively, for the ASDC with $\phi=12 \mathrm{~mm}$ and $\mathrm{r}=75 \mathrm{~mm}$. The comparison with the test results (Figure 3 ) highlights a good matching of the cyclic tests envelopes, although reduced stiffness is recorded in the test data due to the flexibility of the connecting plates and of the test setup, which are not considered in the finite element model; an increased thickness of the connecting plates, as in the detail of Figure $2 \mathrm{c}$, will contribute to reduce their influence to the device global stiffness.

The comparison with the analytical formulation (Figure 5) highlights a good matching of both inplane and out-of-plane yield and ultimate points, although an additional intermediate point is necessary for a better description of the out-of-plane behaviour. This additional point is evaluated at $\left(d_{z, \text { ult }}-d_{z, \text { yield }}\right) / 3$ and the corresponding force depends on the $\phi / r$ ratio (Figure 5 ): 


$$
F_{z, \text { int }}=k_{1} \frac{F_{z, \text { ult }}+2 F_{z, \text { yield }}}{3}=\left(2.193 \frac{\phi}{r}+0.0241\right) \frac{F_{z, \text { ult }}+2 F_{z, \text { yield }}}{3}
$$

The ultimate points have been derived applying equilibrium and are suitable for the analytical formulation of the considered connection, although they do not correspond to strain failure of the connection as indicated in Figure 5. The proposed analytical formulation could be used in ASDC design substituting the characteristic material values with appropriate design values.

\subsection{Global design strategies}

Three different approaches could be adopted for the design of precast beam - roof connections (Palermo et al., 2008): ordinary, partially isolated and isolated solution. The ordinary approach considers the seismic energy dissipation concentrated in the plastic hinges at the base of the columns, while the roof connections are designed as elastic members with an appropriate overstrength value. In the second approach, partially isolated solution, the roof connections are dissipative elements able to contribute to the seismic energy dissipation. This approach helps to decrease the displacements at the column top and therefore the system repair cost after an earthquake. The third approach invokes the isolation of the roof elements from the substructure, as in a bridge deck isolation, limiting the force transmitted from the roof to the columns which could be designed as elastic elements.

In the case of the precast buildings considered herein, only the first two approaches are suitable, in fact these structures have rarely a rigid diaphragm and the relative displacements between roof elements and supporting beams need to be accurately controlled and limited to avoid falling from the support in the case of a floor isolated system at the roof - beam joints.

Therefore two design strategies are suggested. In the first strategy, the ASDC device is designed to remain elastic in a seismic event corresponding to the No-Collapse Requirement (NCR), according to the traditional design approach of roof connections. The advantage of the ASDC compared to traditional connections is associated to its ability of accommodating relative displacements between adjacent elements arising from seismic relative rotations as mentioned before. The second design strategy considers the energy dissipation contribution of the roof connections: the ASDC is designed to yield before the NCR design force obtained with a hinge connection. In this approach, the relative horizontal displacements between roof elements and supporting beam need to be controlled to avoid falling from the support. In order to facilitate the activation of the device the friction in the support area of the roof beam could be reduced.

In the case ASDC is adopted as an additional seismic energy dissipation device in roof elements with traditional hinge connections (Figure 2f), the position of the device which maximizes energy dissipation is at the maximum possible distance from the hinge connection, in order to increase the device horizontal displacements arising from roof element - beam relative rotations. Also the ASDC in-plane configuration should be adopted to maximize energy dissipation because it is characterized by a lower yield displacement and therefore higher displacement ductility compared to the out-of-plane direction. 


\section{Case study application}

To evaluate the efficiency of the ASDC compared to traditional connections, non-linear time history analyses are carried out on a selected case study resembling the precast concrete industrial buildings considered herein. The building plan dimensions are $87.85 \times 76.30 \mathrm{~m}$ and the columns are distributed along the corners of a $17.5 \times 10.9 \mathrm{~m}$ net. The column height is 7.65 $\mathrm{m}$, the cross section is $80 \times 80 \mathrm{~cm}$ with $16 \times 24 \mathrm{~mm}$ diameter rebars, $1.13 \%$ longitudinal ratio. The columns support L-shape and inverted T precast beams in the short span direction, which support double-tee roof elements spanning in the other direction. The concrete 28 days cylindrical strength is $40 \mathrm{MPa}$ and the steel reinforcement yield stress is $450 \mathrm{MPa}$. Different roof - beam connection configurations are considered in the analyses as indicated in Table 1.

In the non-linear time history analyses, only an inner column is modelled. The column tributary mass is $86722 \mathrm{~kg}$. The moment - rotation hysteretic behaviour at the column plastic hinge is described by the Takeda model (Otani, 1974), while a single elasto-plastic element is adopted to describe the behaviour of all the ASDC devices present in the column tributary area. Traditional hinge connections are modelled as linear elastic elements with stiffness according to typical L-shape steel profiles adopted in construction practice.

A set of 7 recorded earthquakes (Table 2) have been selected and scaled from the European Strong Motion Database (Ambraseys et al., 2002) in order to match the elastic spectrum corresponding to the no-collapse requirement with a probability of exceedance $10 \%$ in 50 years (Figure 6): BS EN 1998-1:2004 Type 1 spectrum, soil type C, peak ground acceleration $0.35 \mathrm{~g}$. The non-linear time history analyses results are expressed in Table 3 as the mean plus/minus standard deviation of the maximum values obtained in each ground motion, according to BS EN 1998-1:2004 (BSI, 2005). The connection force and dissipated energy are the sum of the values of all the connections in the inner column tributary area.

The results highlight the overload in traditional hinge connections due to contact between adjacent elements arising from seismic relative rotations. The force in the connection depends on the connection stiffness and on the horizontal gap between the beam and the roof element. The use of ASDC as dissipation device coupled with traditional connections contributes to reducing the column top displacement during a seismic event. If ASDC is adopted in substitution to traditional hinge connections, there is as expected a better control of the connection force and a reduction of column top displacements and dissipated energy, therefore a reduction of the column damage. This reduction increases with lower values of the ASDC activation force. The comparison between ASDC in-plane and out-of-plane configurations shows similar results in terms of column displacements reduction, although slightly higher connection deformations are recorded in the out-of-plane direction due to the lower stiffness of this configuration. 


\section{Conclusions}

The performance of a ductile connection between roof elements and supporting beams is investigated. The selected connection consists of two arch shaped steel rods, it accommodates relative displacements between adjacent elements arising from seismic rotations and dissipates seismic energy. This aspect is often overlooked in design practice and could lead to a fragile failure of the joint depending on the connection stiffness and horizontal gap between adjacent elements.

The experimental tests show a good performance of the connection in both in-plane and out-ofplane directions in terms of strength, ductility and dissipated energy. An analytical formulation of the connection load - displacement backbone curve is provided and compared with the results of the experimental tests and of finite element models. This formulation is necessary for the connection design and finite element modelling.

Two design strategies are proposed: an elastic approach, with the connection designed as elastic in a seismic event corresponding to the No-Collapse Requirement, and a dissipative approach, with the connection designed to yield and dissipate energy. The proposed strategies have been investigated and the performance evaluated by means of non-linear time history analyses. The analyses results show the suitability of the proposed connection to limit the transferred force for both the design strategies; in addition a connection designed to dissipate energy allows limiting the column top displacements, provided connection deformations are specifically evaluated to avoid roof elements loss of support.

\section{Acknowledgements}

The authors express their gratitude to Edilmatic s.r.I. (Pegognaga, Italy) for providing financial support to the experimental campaign. The contribution of Consuelo Beschi Ph.D., Dario Carnevali Eng. and Daniele di Marco in setting up the experimental tests is greatly acknowledged.

\section{References}

Ambraseys N, Smit P, Sigbjornsson R, Suhadolc P and Margaris B (2002) Internet-Site for European Strong-Motion Data. European Commission, Research-Directorate General, Environment and Climate Programme.

Belleri A and Riva P (2012) Seismic performance and retrofit of precast grouted sleeve connections. PCl Journal, 57(1): 97-109.

Blandon JJ and Rodriguez ME (2005) Behavior of Connections and Floor Diaphragms in Seismic Resisting Precast Concrete Buildings. PCI Journal, 50(2): 56-75.

BSI. (2005). BS EN 1998-1:2004. Eurocode 8: Design of structures for earthquake resistance -

Part 1: General rules, seismic actions and rules for buildings. 
Dassault Systèmes Simulia Corp. (2011) ABAQUS user's manual version 6.11.

Felicetti R, Toniolo G and Zenti CL (2008) Experimental investigation on the seismic behaviour of connections in precast structures. In Proceedings of the International FIB symposium, May 19-22, Amsterdam, Netherlands.

Lauciani V, Faenza L and Michelini A (2012) ShakeMaps during the Emilia sequence. Annals of Geophysics, 55(4): 631-637.

Metelli G and Riva P (2008) Seismic behaviour of precast column to foundation joint. In Proceedings of the International FIB symposium, May 19-22, Amsterdam, Netherlands.

Osanai Y, Watanabe F and Okamoto S (1996) Stress Transfer Mechanism of Socket Base Connections with Precast Concrete Columns. ACI Structural Journal, 93(3): 1-11.

Otani S (1974) SAKE: A Computer Program for Inelastic Response of R/C Frames to Earthquakes. Civil Engineering Studies, University of Illinois at Urbana- Champaign, Report SRS-413.

Palermo A, Camnasio E and Poretti M (2008) Role of dissipative connections on the seismic response of one-storey industrial buildings. In Proceedings of the $14^{\text {th }}$ World Conference on Earthquake Engineering, October 12-17, Beijing, China.

Restrepo JI, Park R and Buchanan AH (1995), Design of Connections of Earthquake Resisting Precast Reinforced Concrete Perimeter Frames. PCI Journal, 40(5): 68-80.

Schoettler MJ, Belleri A, Zhang D, Restrepo JI and Fleishman RB (2009) Preliminary results of the shake-table testing for the development of a diaphragm seismic design methodology. PCl Journal, 54(1): 100-124.

Yamada $Y$ and Ezawa $Y$ (1977) On curved finite elements for the analysis of circular arches. International Journal for Numerical Methods in Engineering, 11: 1635-1651.

\section{Figure captions}

Figure 1 - Additional forces in roof element connection due to a change of the static scheme.

Figure 2 - ASDC geometry and possible installation configurations.

Figure 3 - In-plane and out-of-plane experimental test results.

Figure 4 - Connection static scheme for in-plane and out-of-plane deformations.

Figure 5 - In-plane and out-of-plane analytical formulation.

Figure 6 - NCR pseudo acceleration spectra $(\xi=0.05)$.

\section{Table captions}

Table 1 - Considered roof - beam connection configurations.

Table 2 - Selected ground motions for time history analyses.

Table 3 - Non-linear time history analyses results. 
Table 1 - Considered roof - beam connection configurations.

\begin{tabular}{|c|c|}
\hline Model name & Connection configuration \\
\hline$T H C-n c$ & $\begin{array}{l}\text { Traditional hinge connection neglecting contact between adjacent } \\
\text { elements due to connected elements relative rotations }\end{array}$ \\
\hline$T H C-C C$ & $\begin{array}{l}\text { Traditional hinge connections considering contact between } \\
\text { adjacent elements }\end{array}$ \\
\hline$T H C-A S D C$ & $\begin{array}{l}\text { Traditional hinge connections considering contact between } \\
\text { adjacent elements plus ASDC at top of double-tee units (Figure 2f) }\end{array}$ \\
\hline$A S D C$-in-100 & $\begin{array}{l}\text { In-plane ASDC configuration (Figure } 2 \mathrm{e} \text { ) designed to yield under } \\
\text { the connection force obtained in } T H C-n c\end{array}$ \\
\hline$A S D C$-in-80 & $\begin{array}{l}\text { In-plane ASDC configuration designed to yield at } 80 \% \text { of the } \\
\text { connection force obtained in } T H C \text {-nc }\end{array}$ \\
\hline$A S D C$-in-60 & $\begin{array}{l}\text { In-plane ASDC configuration designed to yield at } 60 \% \text { of the } \\
\text { connection force obtained in } T H C \text {-nc }\end{array}$ \\
\hline ASDC-out-100 & $\begin{array}{l}\text { Out-of-plane ASDC configuration (Figure } 2 \mathrm{~d} \text { ) designed to yield } \\
\text { under the connection force obtained in } T H C-n c\end{array}$ \\
\hline ASDC-out-80 & $\begin{array}{l}\text { Out-of-plane ASDC configuration designed to yield at } 80 \% \text { of the } \\
\text { connection force obtained in } T H C-n c\end{array}$ \\
\hline ASDC-out-60 & $\begin{array}{l}\text { Out-of-plane ASDC configuration designed to yield at } 60 \% \text { of the } \\
\text { connection force obtained in } T H C-n c\end{array}$ \\
\hline
\end{tabular}


Table 2 - Selected ground motions for time history analyses.

\begin{tabular}{|c|c|c|c|c|}
\hline Earthquake & Station & $M$ & $\begin{array}{c}\text { Record } \\
\text { code }\end{array}$ & $\begin{array}{l}\text { Scale } \\
\text { factor }\end{array}$ \\
\hline $\begin{array}{c}\text { Alkion } \\
24 / 02 / 1981\end{array}$ & $\begin{array}{l}\text { Korinthos - } \\
\text { OTE Building }\end{array}$ & 6.6 & $000333 x a$ & 1.75 \\
\hline $\begin{array}{c}\text { Alkion } \\
24 / 02 / 1981\end{array}$ & $\begin{array}{l}\text { Korinthos - } \\
\text { OTE Building }\end{array}$ & 6.6 & 000333ya & 1.68 \\
\hline $\begin{array}{c}\text { Adana } \\
27 / 06 / 1998\end{array}$ & $\begin{array}{l}\text { Ceyhan - Tarim } \\
\text { Ilce Mudurlugu }\end{array}$ & 6.3 & $001726 x a$ & 1.83 \\
\hline $\begin{array}{c}\text { Adana } \\
27 / 06 / 1998\end{array}$ & $\begin{array}{l}\text { Ceyhan - Tarim } \\
\text { Ilce Mudurlugu }\end{array}$ & 6.3 & 001726ya & 1.49 \\
\hline $\begin{array}{c}\text { Friuli } \\
15 / 09 / 1976\end{array}$ & Buia & 6 & $000133 x a$ & 3.70 \\
\hline $\begin{array}{c}\text { Alkion } \\
25 / 02 / 1981\end{array}$ & $\begin{array}{l}\text { Korinthos - } \\
\text { OTE Building }\end{array}$ & 6.3 & 000335ya & 3.36 \\
\hline $\begin{array}{c}\text { Kefallinia } \\
23 / 03 / 1983\end{array}$ & Lefkada -Hospital & 5.2 & 000348ya & 12.93 \\
\hline
\end{tabular}


Table 3 - Non-linear time history analyses results.

\begin{tabular}{|l|c|c|c|c|c|}
\hline Configuration & $\begin{array}{c}\text { Column top } \\
\text { displacement } \\
{[\mathbf{m m}]}\end{array}$ & $\begin{array}{c}\text { Connection } \\
\text { displacement } \\
{[\mathbf{m m}]}\end{array}$ & $\begin{array}{c}\text { Connection } \\
\text { force } \\
{[\mathbf{k N}]}\end{array}$ & $\begin{array}{c}\text { Column base } \\
\text { dissipated } \\
\text { energy } \\
\text { [kJ] }\end{array}$ & $\begin{array}{c}\text { Connection } \\
\text { dissipated } \\
\text { energy } \\
\text { [kJ] }\end{array}$ \\
\hline THC-nC & $128.9 \pm 24.3$ & $14.9 \pm 0.8$ & $223 \pm 13$ & $44.5 \pm 18.1$ & 0 \\
\hline THC-cC & $103.7 \pm 18.7$ & $24.8 \pm 2.2$ & $372 \pm 33$ & $33.1 \pm 21.6$ & 0 \\
\hline THC-ASDC & $123.2 \pm 18.7$ & $11.6 \pm 1.4$ & $168 \pm 9$ & $53.2 \pm 18.9$ & $22.2 \pm 5.3$ \\
\hline ASDC-in-100 & $101.1 \pm 46.0$ & $0.6 \pm 0.5$ & $241 \pm 7$ & $50.0 \pm 28.9$ & $0.3 \pm 0.5$ \\
\hline ASDC-in-80 & $117.0 \pm 14.2$ & $4.9 \pm 0.6$ & $237 \pm 7$ & $48.3 \pm 18.3$ & $4.2 \pm 2.5$ \\
\hline ASDC-in-60 & $115.8 \pm 14.8$ & $9.9 \pm 0.7$ & $233 \pm 7$ & $41.3 \pm 14.5$ & $11.4 \pm 5.3$ \\
\hline ASDC-out-100 & $121.6 \pm 16.3$ & $1.1 \pm 0.5$ & $234 \pm 7$ & $53.7 \pm 19.5$ & $0.1 \pm 0.2$ \\
\hline ASDC-out-80 & $119.6 \pm 16.2$ & $5.6 \pm 0.9$ & $230 \pm 7$ & $48.6 \pm 17.0$ & $4.2 \pm 2.7$ \\
\hline ASDC-out-60 & $113.7 \pm 14.9$ & $14.1 \pm 1.0$ & $225 \pm 7$ & $38.3 \pm 12.3$ & $14.5 \pm 6.8$ \\
\hline
\end{tabular}




\section{Figures}

Figure 1 - Additional forces in roof element connection due to a change of the static scheme.

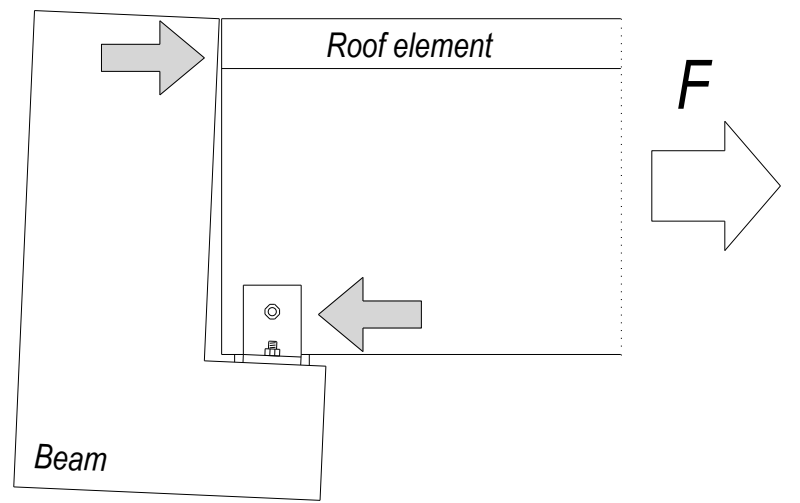


Figure 2 - ASDC geometry and possible installation configurations.

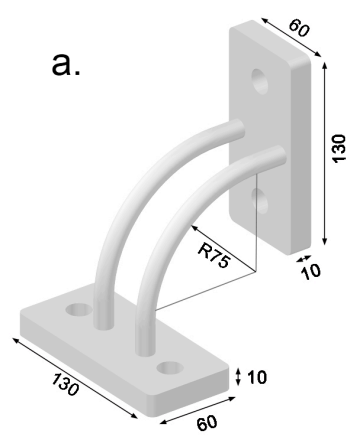

welding types

욤

b.

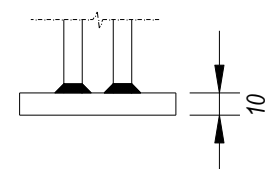

c.
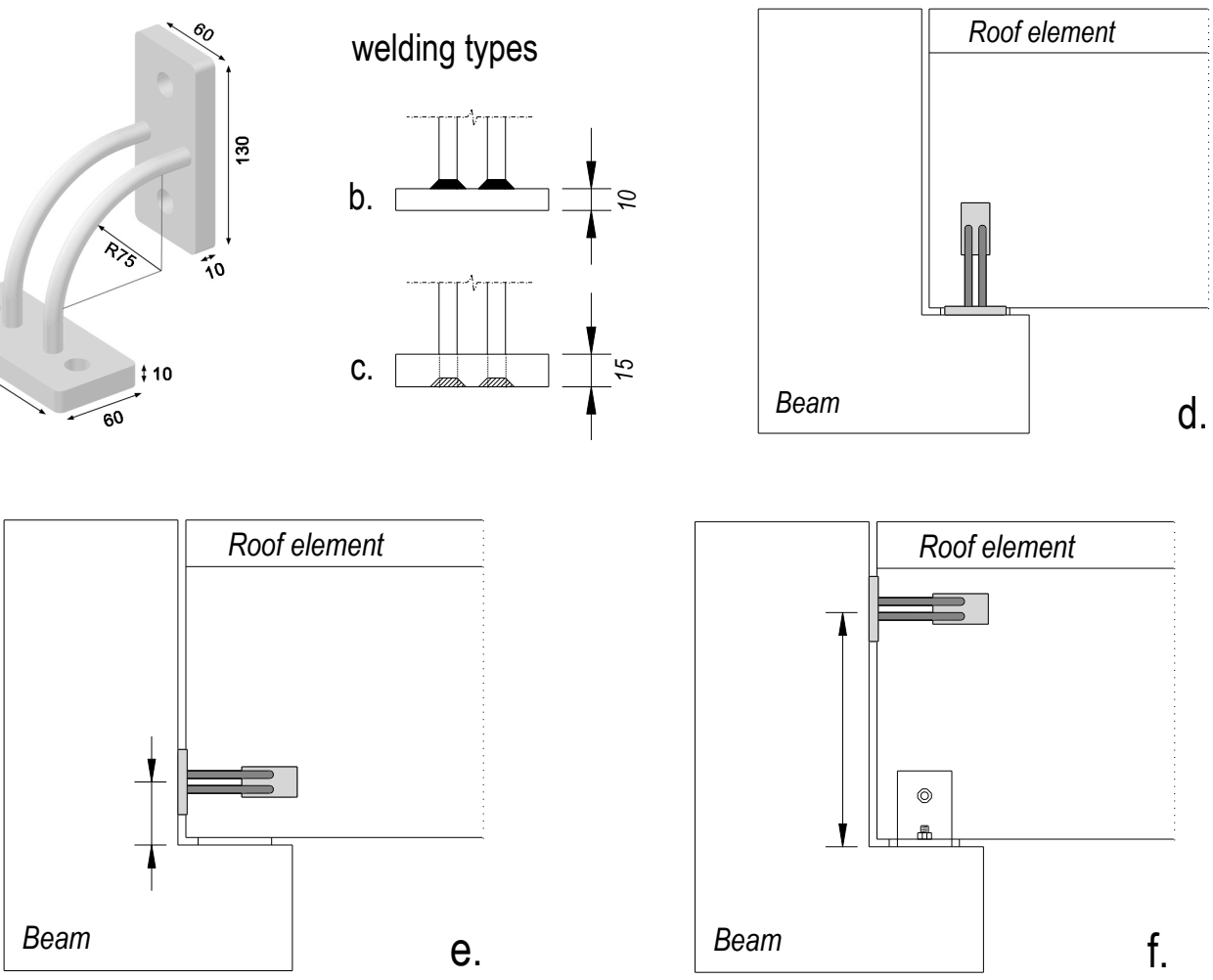
Figure 3 - In-plane and out-of-plane experimental test results.
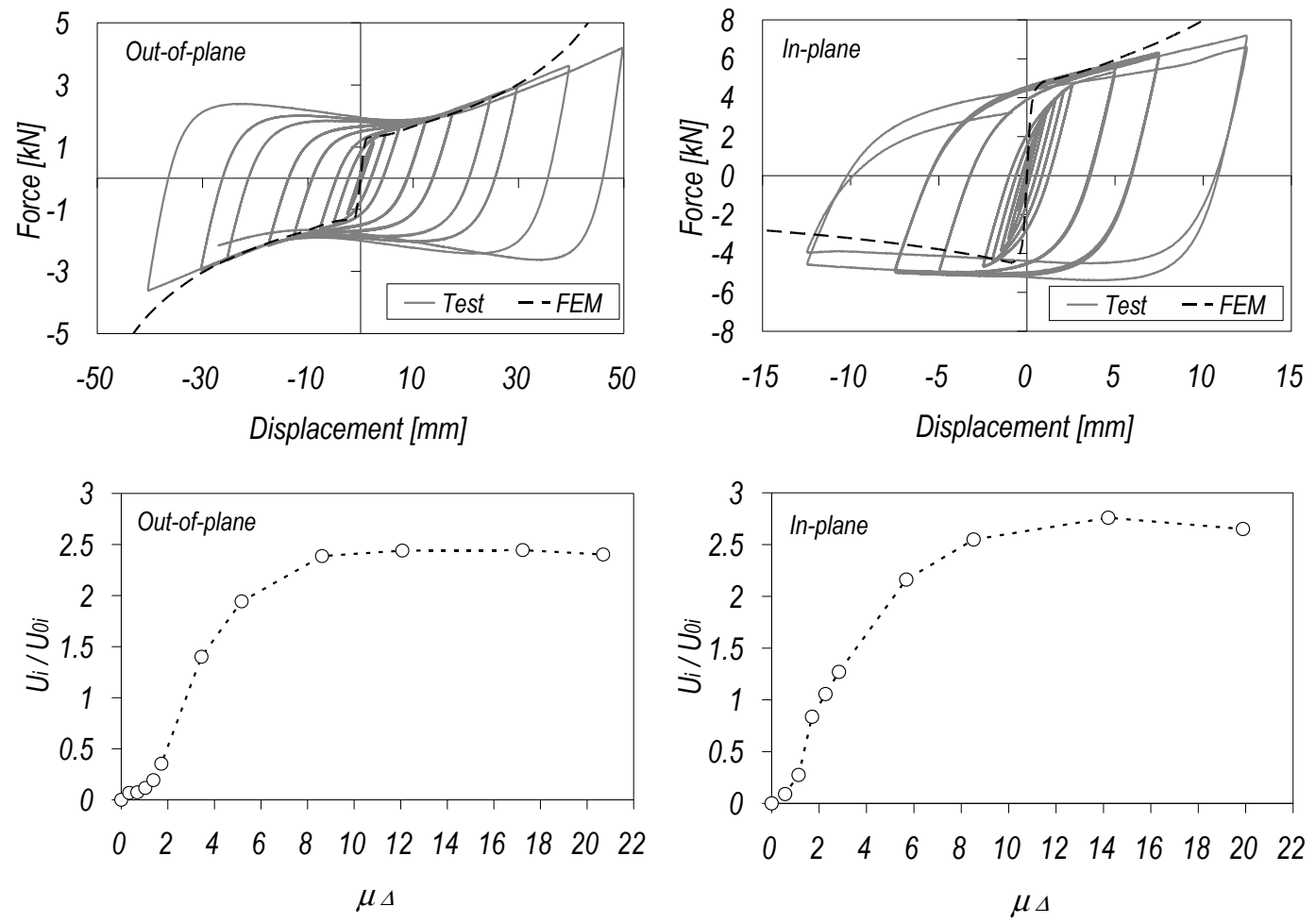
Figure 4 - Connection static scheme for in-plane and out-of-plane deformations.

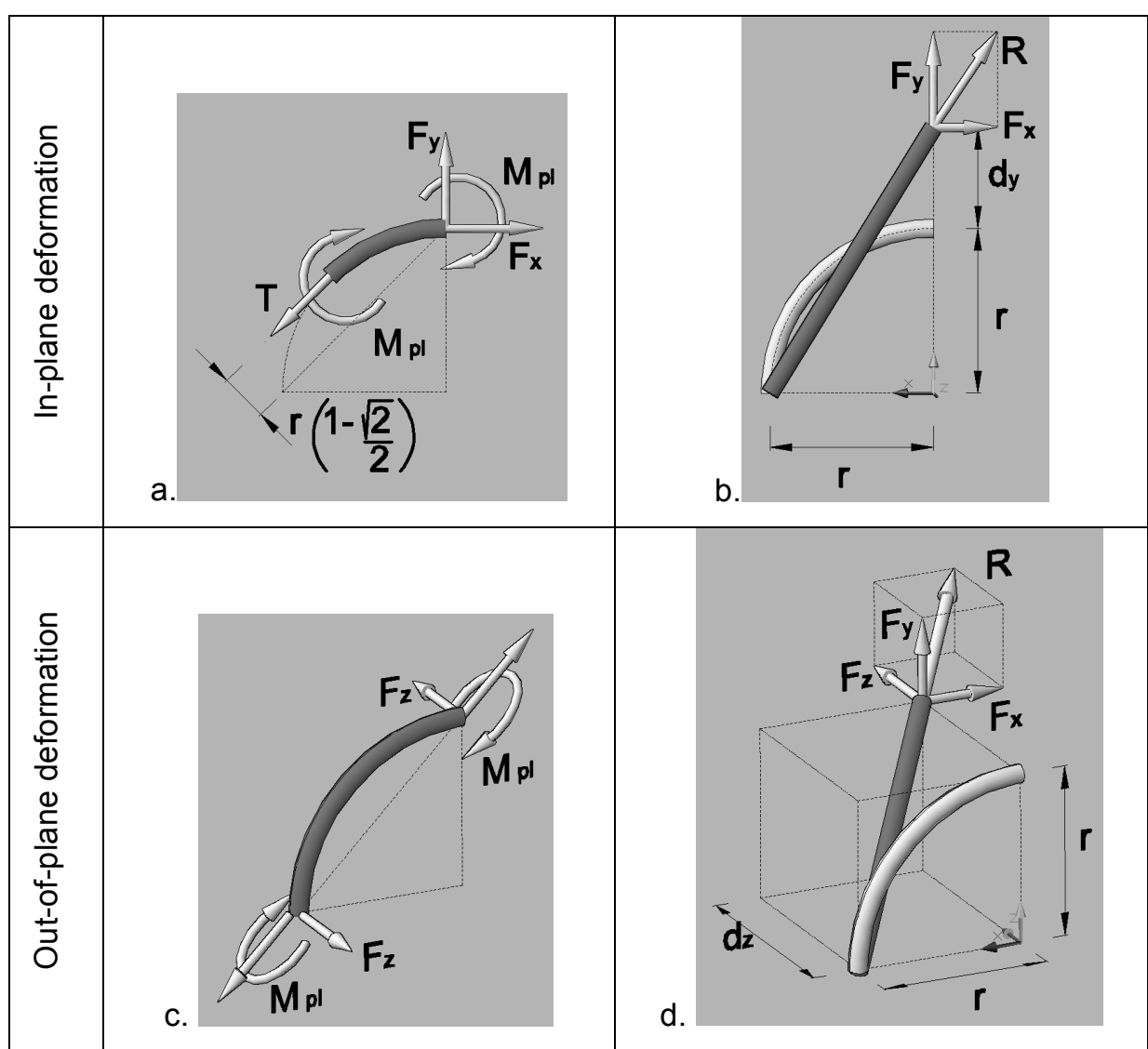


Figure 5 - In-plane and out-of-plane analytical formulation.
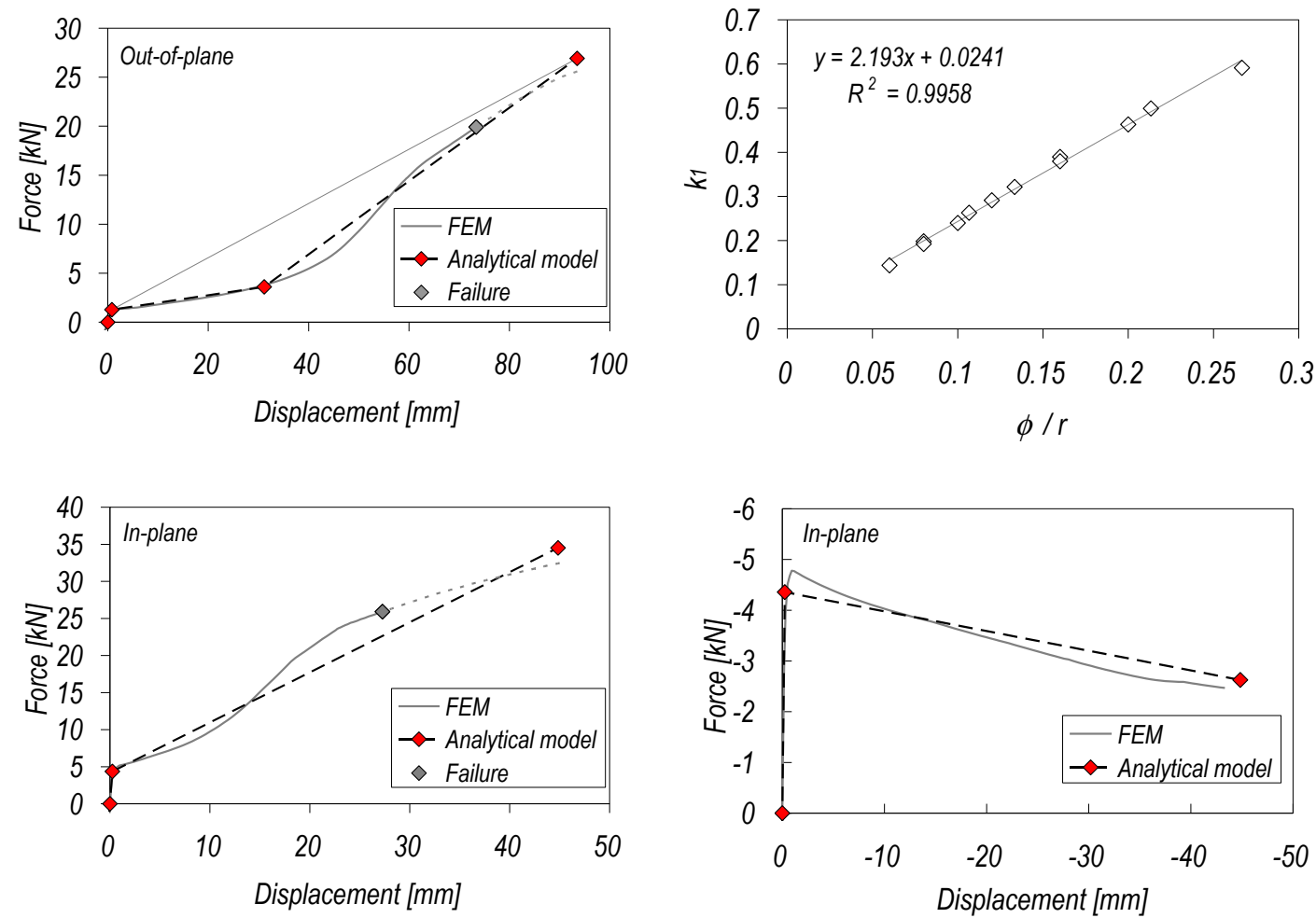
Figure 6 - NCR pseudo acceleration spectra $(\xi=0.05)$.

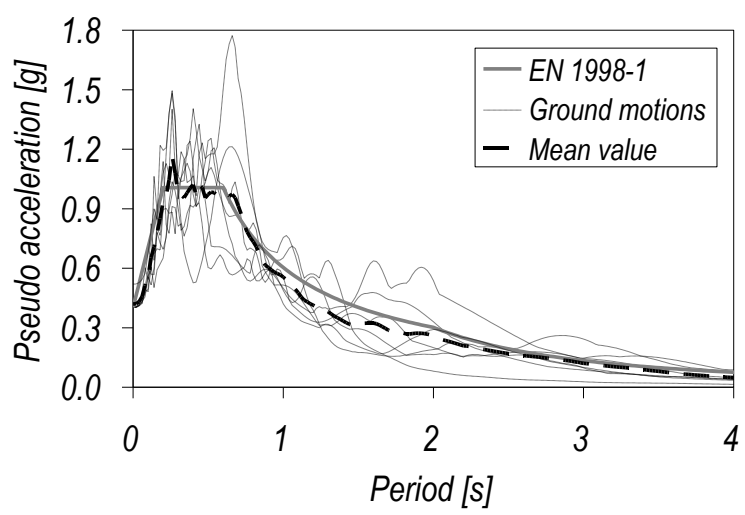

